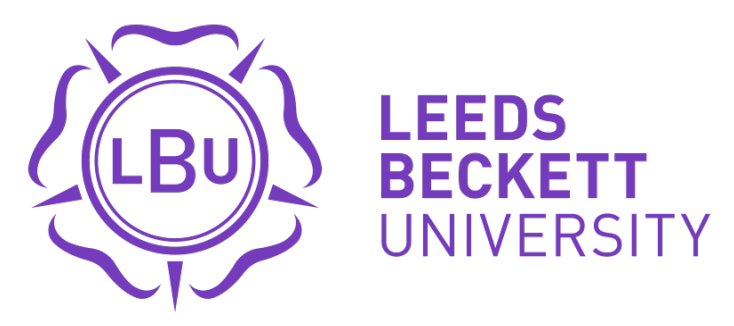

Citation:

Casado, A and Hanley, B and Ruiz-Pérez, LM (2020) Deliberate Practice in Training Differentiates the Best Kenyan and Spanish Long-Distance Runners. European Journal of Sport Science, 20 (7). pp. 887-895. ISSN 1536-7290 DOI: https://doi.org/10.1080/17461391.2019.1694077

Link to Leeds Beckett Repository record:

https://eprints.leedsbeckett.ac.uk/id/eprint/6358/

Document Version:

Article (Accepted Version)

This is an Accepted Manuscript of an article published by Taylor \& Francis in European Journal of Sport Science on 21 Nov 2019, available online: http://www.tandfonline.com/10.1080/17461391.2019.1694077

The aim of the Leeds Beckett Repository is to provide open access to our research, as required by funder policies and permitted by publishers and copyright law.

The Leeds Beckett repository holds a wide range of publications, each of which has been checked for copyright and the relevant embargo period has been applied by the Research Services team.

We operate on a standard take-down policy. If you are the author or publisher of an output and you would like it removed from the repository, please contact us and we will investigate on a case-by-case basis.

Each thesis in the repository has been cleared where necessary by the author for third party copyright. If you would like a thesis to be removed from the repository or believe there is an issue with copyright, please contact us on openaccess@leedsbeckett.ac.uk and we will investigate on a case-by-case basis. 
Publisher: Taylor \& Francis \& European College of Sport Science

Journal: European Journal of Sport Science

DOI: $10.1080 / 17461391.2019 .1694077$

\section{Deliberate Practice in Training Differentiates the Best Kenyan and SPANISH LONG-DiSTANCE RUNNERS}

Arturo Casado ${ }^{1}$, Brian Hanley ${ }^{2}$ and Luis Miguel Ruiz-Pérez ${ }^{3}$

\footnotetext{
${ }^{1}$ Faculty of Health Sciences, University Isabel I, 09004 Burgos, Spain

${ }^{2}$ Carnegie School of Sport, Leeds Beckett University, United Kingdom

${ }^{3}$ Department of Social Sciences of Physical Activity and Sports, Politécnica University of Madrid UPM, Madrid, Spain
}

Corresponding author: Dr Arturo Casado, Faculty of Health Sciences, University Isabel I, 09004 Burgos, Spain. Calle Fernán González, 76; 09003; Burgos, Spain

Email: arturocasado1500@gmail.com

Twitter: @ ArturoCasadoAld 


\begin{abstract}
The aim of this novel research was to compare the amount of systematic training and the different training activities undertaken by elite-standard long-distance runners during their first seven years of systematic training. Participants were divided into three performance groups: world-class Kenyans $(\mathrm{N}=19)$, European-standard Spanish athletes $(\mathrm{N}=18)$, and Spanish national-standard athletes $(\mathrm{N}=18)$. Performance and training data were obtained for two-year periods using retrospective recall (including training diaries) from the time the athletes began systematic training, until the seventh year after. These activities included high-intensity training sessions considered deliberate practice (DP) and easy runs. There was no evidence that starting systematic training at a younger age was advantageous, and easy runs (a non-DP activity) were the most used by participants as a proportion of overall running distance. As part of an overall higher accumulation of distance run $(P<0.001, d \geq 1.35)$, the Kenyans completed more tempo runs and short-interval training than the other groups $(P<0.001, d \geq 1.38)$, but did not complete more long intervals or races. There were few differences between the European- and national-standard athletes except for easy runs, which highlights the value of these easy runs but also the need for higher-intensity training to compete with world-class performers. When planning for training overload and progression, long-distance running coaches should consider increasing the volume of tempo runs and short intervals, in addition to easier runs that develop cardiovascular conditioning.
\end{abstract}

Keywords: Training, Endurance, Coaching, Performance. 


\section{INTRODUCTION}

Some decades ago, deliberate practice (DP) theory was founded by Ericsson, Kramp, and Tesch-Römer (1993) in their study of musicians, finding that those who engaged persistently with this kind of practice played at a higher standard (Ericsson et al., 1993). According to Ericsson (2013), improvements arise from both natural maturation and DP, where DP is considered as requiring full concentration, designed to improve a particular aspect of performance, and with opportunities for gradual refinement. Nowadays, DP is considered crucial to achieve excellence and best performances in any field (Baker \& Young, 2014; Ericsson, 2013), and within sporting contexts this kind of practice is characterised by considerable physical and cognitive efforts that are highly relevant from the athlete's perspective in improving competitive performance and inherent enjoyment (Young \& Salmela, 2002). The DP framework proposes that skill is predominantly determined by the amount of DP completed (Ericsson et al., 1993), but many excellent sports performances do not rely predominantly on fine motor skills (as in musicianship) but rather on superior physiological traits. Within long-distance running, these traits include better maximal oxygen uptake, running economy and lactate threshold (Midgley, McNaughton \& Jones, 2007), and much of a distance runner's training regimen focusses upon improving these determinants. The types of training that would be considered DP with regard to specifically developing these physiological factors could include interval training (multiple repetitions of a set distance at a high percentage of maximal oxygen uptake) and tempo runs (sustained efforts at lactate threshold pace) (Billat et al., 2003).

One of the world's most dominant nations in long-distance running is Kenya; as of December $2018,45 \%$ of athletes in the top 10 in historical world rankings in the long-distance events of the 5,000 m, 10,000 m, half-marathon and marathon represented that nation (IAAF, 2018). In 
the marathon alone, 53 of the top 100 finishing times of all time were run by Kenyans (IAAF, 2018). As some researchers have argued that differences in variance of performance are only partially explained by DP (Hambrick et al., 2014; MacNamara, Hambrick, \& Oswald, 2014; MacNamara, Moreau, \& Hambrick, 2016), the current trend in DP theory argues more for a multifactorial explanation of different performances (MacNamara et al., 2016), which applies to the Kenyan long-distance success phenomenon. For example, Wilber and Pitsiladis (2012) reviewed the most seemingly important aspects: physiology, genetics, biomechanics, nutrition, altitude and psychology. In this particular review, DP was not mentioned, but it is likely that it had some relevance given the need to train specifically to develop particular skills and attributes (physiological as well as technical and tactical). Casado and Ruiz (2017) and Casado et al. (2014) studied the perceptions of Kenyan and Spanish elite-standard long-distance runners from the DP framework, finding that the Kenyan runners who were the best in the world reported higher physical exertion, mental effort, and enjoyment in specific training activities (short- and long-interval workouts, tempo runs, and races / time trials) than Spanish runners. It has yet to be reported whether successful Kenyan distance runners undertake more of these higher-intensity sessions than less-successful (but still elite-standard) athletes, and a novel study on such training regimens would clearly benefit coaches across distance running events in informing them of the balance required between DP-related training activities and less taxing, "easy" runs, or other forms of training. The aim of this novel research was to compare the amount of practice (systematic training) and the kind of practice (different training activities) undertaken by different standards of long-distance runners during the first seven years of systematic training. 


\section{MATERIAL AND METHODS}

\section{Participants}

The participants were 55 male elite-standard long-distance runners (19 Kenyan runners and 36 Spanish runners). The age range was between 18 and 42 years old, with a mean of 28.8 years $( \pm 5.3)$. All participants were specialists in the 5,000 m, 10,000 m, half marathon $(21.097 \mathrm{~km})$ or marathon $(42.195 \mathrm{~km})$. At the time of the research, all participants were competing in at least one of these events.

Because participants competed over different distances, they were assigned to one of three performance groups based on their personal performance record seven years into their career using the International Association of Athletics Federations (IAAF) performance scoring tables (Spiriev, 2017). These tables assign a score to each performance, enabling comparisons between events (Legaz \& Eston, 2005). The period of seven years into their career was chosen because some participants did not provide data before this duration. The world-class Kenyan group ("Kenyans") comprised 19 Kenyan athletes ( $26.8 \pm 3.1$ years) whose performance scores ranged between 1,145 and 1,284 points. Among them were medallists in the World Cross Country Championships, World Marathon Championships, Olympic Games, Commonwealth Games and African Championships. These runners' best times ranged from 2:03:23 (a former world record holder) to $2: 10: 23$ in the marathon, and from 58:54 to 1:01:10 in the half marathon; the current world record holder for $10 \mathrm{~km}$ road running (26:44) also participated. The European-standard Spanish group (“Europeans") comprised 18 Spanish athletes (33.3 \pm 4.4 years) whose performance scores ranged between 1,002 and 1,196 points. Among them were medallists in the European Cross-Country Championships and European Championships (track). These runners' best times ranged from 2:08:09 to 2:16:02 in the marathon, and from 1:01:18 to 1:04:46 in the half marathon. The national-standard Spanish group ("Nationals") 
comprised 18 Spanish athletes (26.5 \pm 5.4 years) whose performance scores ranged between 674 and 1,010 points. Among them were Spanish national 10,000 $\mathrm{m}$ and half marathon championships medallists. These runners' best times ranged from 2:17:50 to 2:25:37 in the marathon, and from 1:04:56 to 1:11:25 in the half marathon.

All participants provided informed consent to take part in the study, which was approved by the Institutional Review Board, and conducted in accordance with the declaration of Helsinki.

\section{Data analysis}

To measure the participants' amount of practice or systematic training during their sports career, a taxonomy of training activities questionnaire (TTAQ) was developed based on the questionnaire of Young \& Salmela (2002, 2010), developed for middle-distance runners. This instrument was based on the proposal of Ericsson et al. (1993), adapted for long-distance running and validated by three experienced long-distance running coaches.

Participants completed a three-part questionnaire. The first part asked for biographical information, current age, starting age for systematic training, athletics event competed in and personal performance records. In the second part, participants were asked to recall quantitative and performance information; participants gave information about systematic practice at the starting age and at progressive two-year intervals from that time onwards (i.e., at years 3, 5 and 7) until the present. At each time interval, participants were asked to report how much time they had engaged in different training activities (not running), or what distances they had run in different running training activities during a typical week of training 10 weeks before their season goal race or championships (national championships, European Championships, Olympic Games, etc.). This parameter was suggested by experienced coaches in the field 
(Young \& Salmela, 2010). The relevant training activities included cross training, flexibility training, weight training, work with a coach, easy runs, tempo runs, long-interval training, short-interval training and race / time trials (Casado \& Ruiz, 2017; Casado et al., 2014; Young $\&$ Salmela, 2010). For each of the latter five activities, participants were further instructed to account for total weekly running distance $(\mathrm{km})$, as running distance rather than time is the measure most often collected by elite-standard runners (Young \& Salmela, 2010). Likewise, the latter four activities were those that participants considered more important and, in this study, were considered as DP. This decision was taken because these same participants rated these activities with high values (means greater than 7 in a 10-point Likert-type scale) and higher than the midpoint of the scale (5) in relevance, physical and mental effort, and enjoyment $(P<0.001$, Cohen's $d \geq 1.86)$ in two previous research studies (Casado \& Ruiz, 2017; Casado et al., 2014). Meanwhile, weight training and work with a coach were excluded because more than $80 \%$ of Kenyan participants neither trained in a gymnasium nor had a coach (Casado \& Ruiz, 2017; Casado et al., 2014). Accordingly, measures of practice were calculated only in the activities that were either considered by participants as DP or as easy runs to calculate total distance covered on the basis of self-reported relevance (mean above 7 in the Likert-type scale and higher than the midpoint of the scale) to perform adequately during competitions $(P<0.001, d=2.24)$. Easy runs were considered as mentally effortless, as its rating by participants was not higher than the midpoint (5) for concentration $(P=0.06, d=$ 0.27) (Casado \& Ruiz, 2017; Casado et al., 2014). Definitions of the different activities studied are:

- Tempo run: Continuous running at a relatively high-intensity pace (half marathon to marathon pace).

- Short-interval training: High-intensity pace repetitions (1,500 $\mathrm{m}$ to 5,000 m pace).

- Long-interval training: High-intensity pace repetitions (5,000 m to $10,000 \mathrm{~m}$ pace). 
Subsequently, participants were required to account for best times in competitions after 1, 3, 5, and 7 years of systematic training. As $73.4 \%$ of participants did not report performance times for the first year of systematic training, this stage was not included in the analysis.

In the third part of the questionnaire, participants assessed the number of weeks of no training or full rest during their sports career. In this way, an assessment of the number of training weeks per year was possible. As undertaken by Young and Salmela (2010), at the beginning year of systematic training, typical hours of involvement per week were multiplied by the weeks per year to derive the annual amounts, which were then doubled to account for the twoyear interval total, and these totals were then summed for accumulated amounts of practice at three years (i.e., including the beginning-year value, plus the interpolated value for the next two years), and so forth (Ericsson et al., 1993; Hodges \& Starkes, 1996).

$78.7 \%$ of the participants indicated that they used a training log to help them complete the questionnaire. Some athletes did not keep hold of the training information; rather, their coaches recorded these data. In this regard, Baker, Côté, and Deakin (2005) demonstrated the reliability of the "training journal method" for supporting recall for athletes in individual sports. Furthermore, this retrospective recall technique has already been used with musicians (Ericsson et al., 1993), triathletes and swimmers (Hodges, Kerr, Weir, \& Nananidou, 2004) and middledistance runners (Young \& Salmela, 2010). Additionally, different studies have demonstrated high reliability regarding the long-term recall of individuals engaging in physical and sports activities (Blair et al., 1991; Falkner, Tervisan, \& McCann, 1999; Hayman, Polman, \& Taylor, 2012; Helsen et al., 1998). 


\section{Statistical analysis}

Statistical analyses of data were performed using SPSS 24.0. Data were checked for normality of distribution, homogeneity of variances and sphericity assumptions as appropriate. When the sphericity assumption was violated, Greenhouse-Geisser corrections were employed. A oneway ANOVA was used to compare the starting ages of systematic training among the performance groups. If this variable was found to be significantly different between groups, it was considered a covariate for the ANOVAs comparing accumulated practice at the interaction of time and performance. Two-way (standard x time) repeated-measures ANOVAs were employed for comparing performances (using IAAF scoring points), specific individual running activities (i.e., easy runs, tempo runs, long-interval training, short-interval training and races / time trials), and for total amounts of accumulated distance. The same assessment was conducted for the percentage of the total accumulated distance that represented each training activity at each stage. Where appropriate, post hoc pairwise comparisons between groups were made with Bonferroni corrections. Statistical significance was set at $P<0.05$. Effect sizes (ES) were calculated using partial eta-squared $\left(\eta_{\mathrm{p}}{ }^{2}\right)$ for the ANOVA tests, and Cohen's $d$ (Cohen, 1988) for the post hoc analyses. The latter was considered to be either small $(0.21-0.60)$, moderate $(0.61-1.20)$, large $(1.21-2.00)$, very large $(2.01-4.00)$ or nearly perfect $(>4.00)$ (Hopkins, Marshall, Batterham \& Hanin, 2009). Differences were considered to occur when $P$ $<0.05$ and Cohen's $d$ displayed at least a moderate effect $(d \geq 0.61)$.

\section{RESULTS}

There were significant differences in the starting age of systematic training between the Kenyans $(18.9 \pm 3.1$ years $)$, Europeans $(16.1 \pm 3.2$ years old $)$, and Nationals $(13.1 \pm 2.6$ years old $)(P<0.001)$. The Kenyans' starting age was higher than the Europeans' $(P=0.016, d=$ 
$0.90)$ and Nationals' ages $(P<0.001, d=1.86)$, and the Europeans' starting age was higher than the Nationals' age $(P=0.044, d=0.87)$. Thus, this variable was considered a covariate.

The group $\mathrm{x}$ time interaction effect for total volume of distance run was significant $(P=0.002$, $\left.\eta_{\mathrm{p}}{ }^{2}=0.211\right)$ and increased with time $(P<0.001)$. The Kenyans' total volume was always higher than the Europeans' $(P<0.001, d$ from 1.35 to 1.56$)$ and Nationals' totals $(P<0.001$, $d$ from 3.30 to 3.56 ). The Europeans' total was higher than the Nationals' total at all stages (from $P=0.004$ to $P=0.013, d$ from 1.02 to 1.09 ) (Figure $1 \mathrm{~A}$ ). 

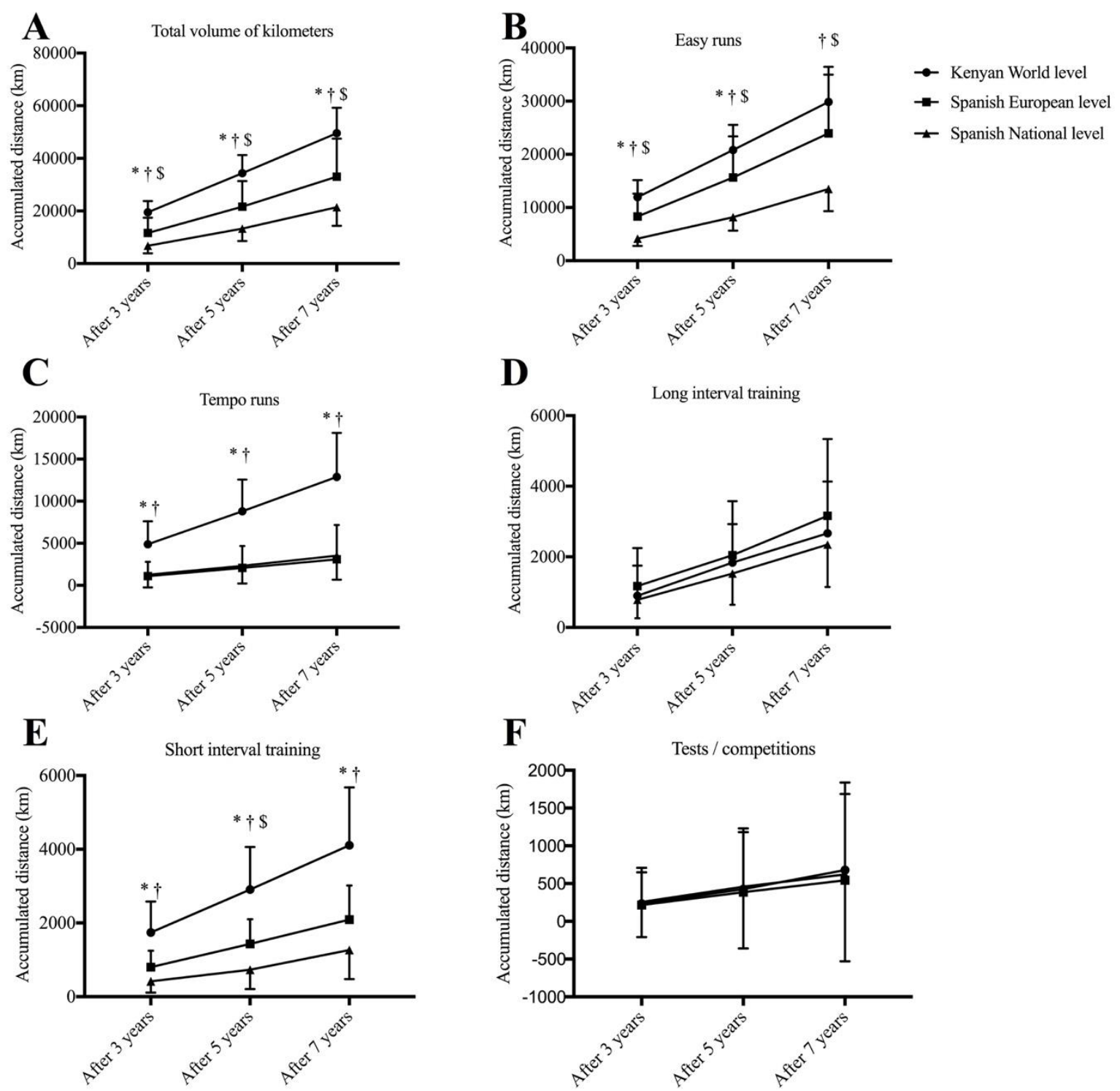

Figure 1A-E. Means and standard deviations for accumulated amounts of total volume of distance run (A), easy runs (B), tempo runs (C), long-interval training (D), short interval training (E) and tests and competitions (F) by performance group over seven years. Significant differences with at least moderate effects $(P<0.05$ and $d \geq 0.61)$ are annotated between Kenyans and Europeans $(*)$, between Kenyans and Nationals $(\dagger)$, and between Europeans and Nationals (\$). 
The group $\mathrm{x}$ time interaction effect for performance (IAAF scoring points) was significant ( $P$ $\left.=0.039, \eta_{\mathrm{p}}{ }^{2}=0.098\right)$. Performance increased across time of systematic training at all stages $(P$ $<0.001)$. At all stages, the Kenyans' performance scores were higher than both the Europeans' $(P<0.001, d$ from 1.46 to 1.99$)$ and the Nationals' scores $(P<0.001, d$ from 3.58 to 4.14$)$; additionally, the Europeans' scores were higher than the Nationals' scores at all stages $(P<$ $0.001, d$ from 1.39 to 1.48 ) (Figure 2A).

The group $\mathrm{x}$ time interaction effect for accumulated easy runs was significant $\left(P<0.015, \eta_{\mathrm{p}}{ }^{2}=\right.$ $0.048)$ and increased across time $(P<0.001)$. The Kenyans' accumulated distance was higher than the Europeans' value after three and five years of systematic training (from $P<0.001$ to $P=0.016, d$ from 0.81 to 0.97$)$ but did not differ after seven years $(P=0.075)$. The Kenyans' values were always higher than the Nationals' values ( $P<0.001, d$ from 2.97 to 4.76$)$, as were the Europeans' values (both $P<0.001, d$ from 1.26 to 1.31) (Figure 1B). The group x time interaction effect for the percentage of accumulated easy runs from accumulated total distance was not significant $\left(P=0.843, \eta_{\mathrm{p}}^{2}=0.009\right)$ (Figure $\left.2 \mathrm{~B}\right)$.

The group $\mathrm{x}$ time interaction effect for accumulated tempo runs was also significant $(P<0.001$, $\left.{ }^{2}=0.441\right)$ and increased across time $(P<0.001)$. At all stages, the Kenyans' accumulated tempo run distance was higher than the Europeans' and Nationals' distances $(P<0.001, d$ from 1.75 to 2.38$)$, whereas the Europeans' and Nationals' values did not differ at any stage $(P=$ 0.99) (Figure 1C). The group $x$ time interaction effect for the percentage of accumulated tempo runs from accumulated total distance was not significant $\left(P=0.778, \eta_{\mathrm{p}}{ }^{2}=0.017\right)$; however, the main group effect was significant $\left(P<0.001, \eta_{\mathrm{p}}{ }^{2}=0.398\right)$. At all stages, the Kenyans' percentage of accumulated tempo runs was higher than the Europeans' and Nationals' percentages ( $P=0.008, d$ from 1.11 to 1.96$)$ (Figure $2 \mathrm{C}$ ). 
There was no group $\mathrm{x}$ time interaction effect for accumulated long-interval training $(P=0.225$, $\left.\eta_{\mathrm{p}}{ }^{2}=0.056\right)$, but the main time effect was significant for all groups $\left(P<0.001, \eta_{\mathrm{p}}{ }^{2}=0.715\right)$ in that it increased with time (see Figure 1D). There was no group $\mathrm{x}$ time interaction effect for percentage of accumulated long interval training from accumulated total distance $(P=0.375$, $\left.\eta_{\mathrm{p}}{ }^{2}=0.056\right)$; however, the main group effect was significant $\left(P=0.010, \eta_{\mathrm{p}}{ }^{2}=0.237\right)$. At all stages, the Kenyans' percentage of accumulated long interval training was higher than the Nationals' percentage ( $P=0.004, d$ from 1.23 to 1.35$)$ (Figure 2D).

The group $\mathrm{x}$ time interaction effect for accumulated short-interval training was significant $(P$ $\left.<0.001, \eta_{\mathrm{p}}^{2}=0.339\right)$ and increased across time $(P<0.001)$. The Kenyans' values were always higher than the Europeans' $(P<0.001, d$ from 1.38 to 1.55$)$ and Nationals' values $(P<0.001$, $d$ from 2.06 to 2.27 ); the Europeans' values were only higher than the Nationals' values after five years of systematic training, however $(P=0.045, d=1.17)$ (Figure 1E). The group $\mathrm{x}$ time interaction effect for the percentage of accumulated short interval training from accumulated total distance was not significant $\left(P=0.718, \eta_{\mathrm{p}}^{2}=0.022\right)$ (Figure 2E). 



Figure 2A-E. Means and standard deviations for performance (IAAF scoring points) displayed by performance group over seven years (A). Means and standard deviations for the percentage of accumulated amounts of easy runs (B), tempo runs (C), long interval training (D), short interval training $(\mathrm{E})$ and tests and competitions $(\mathrm{F})$ from the total volume of distance run by performance group over seven years. Significant differences with at least moderate effects $(P$ $<0.05$ and $d \geq 0.61)$ are annotated between Kenyans and Europeans $(*)$, between Kenyans and Nationals $(\dagger)$, and between Europeans and Nationals $(\$)$. 
There was no group $\mathrm{x}$ time interaction effect for accumulated tests and competitions $(P=0.972$, $\left.\eta_{\mathrm{p}}{ }^{2}=0.001\right)$; however, the main time effect was significant $\left(P=0.001, \eta_{\mathrm{p}}{ }^{2}=0.212\right)$ and increased across time (Figure 1F). The group x time interaction effect for the percentage of accumulated tests and competitions from accumulated total distance was not significant $(P=$ $\left.0.361, \eta_{\mathrm{p}}^{2}=0.053\right)($ Figure $2 \mathrm{~F})$.

\section{DISCUSSION}

The aim of this new research was to compare the amount of practice (systematic training) and the kind of practice (different training activities) undertaken by world-class and elite-standard long-distance runners during their first seven years of systematic training. The starting age of systematic training was youngest in the lowest performing group, and oldest in the more successful Kenyans, disagreeing with the original findings of DP (Ericsson et al., 1993) regarding the importance of early specialisation in achieving best performances. Systematic training therefore does not need to begin early to be a successful athlete, but of course most athletes will very likely have taken part in a great amount of running before beginning training specifically for competition.

There were two aspects to the analyses conducted in the study: first, the change with time in performance scores, distance run and percentage of the total distance covered per type of training session; and second, the differences between standards of athletes at each time point. Performance scores continually improved in all groups, and always differed between groups (Figure 2A). The high proportion of time spent by athletes of all standards on DP training sessions confirm that DP activities had an influence on performances in these prominent athletes, as reported for team sports (Helsen et al., 1998), martial arts (Hodge \& Deakin, 1998) and triathlon (Baker et al., 2005; Hodges et al., 2016). In this study, four types of training were 
considered DP: tempo runs, long-interval training, short-interval training and race / time trials. At each time point, the Kenyans had accumulated more tempo runs and short-interval training distances than either group of Spanish athletes. Research that previously examined elitestandard Kenyan runners' training similarly highlighted the importance of tempo runs (between 45 and 70 min in duration) to the runners' training system (Billat et al., 2003). The considerable amount of distance covered as tempo runs, especially after seven years, clearly differentiated the training of the Kenyan participants from the Spanish athletes (Figure 1C). Even more so, the proportion of accumulated tempo runs with respect to accumulated total distance was higher in the Kenyans than in the Spanish runners at all stages (Figure 2C). Tempo runs might be particularly important in long-distance running in terms of racing at a consistent pace, especially given the most successful athletes in world marathon and cross-country championships maintain even paces (or at least more so than their rivals) (Hanley, 2016; Hanley, 2018). Furthermore, short-interval training was practised more by Kenyan runners than the other groups, but differed between the European and Nationals groups only after five years of systematic training. By contrast, neither long-interval training nor race / time trial amounts differed between groups at any stage, which is not to suggest that these forms of running do not provide important training stimuli, but reinforces the findings that Kenyan training methods emphasise tempo running and short intervals for improving performance.

As well as with high-intensity training volumes, easy running accounted for most of the total running volume by participants during the first seven years of systematic training, even though they did not consider it DP because they rated it as mentally effortless (Casado \& Ruiz, 2017; Casado et al., 2014). It is unsurprising that the importance of easy runs on performance in middle- and long-distance running has previously been shown in studies that have focused on training intensity distribution in endurance sports (Kenneally, Casado, \& Santos-Concejero, 
2018; Stöggl \& Sperlich, 2015). This finding contradicts the original theory of DP (Ericsson et al., 1993), acknowledging the considerable usage of physically and mentally effortless activities such as easy runs by elite-standard and world-class endurance runners. Therefore, DP seems to dismiss the important role of low intensity training in the enhancement of physiological determinants of endurance exercise performance, which might not be needed in the acquisition of motor skills. The best Spanish runners (European group) also completed considerable amounts of easy runs after seven years of systematic training (not different from the Kenyans), and their greater overall accumulated distance than the Nationals group was largely because of completing more easy runs. Interestingly, the proportions of practice of each activity with respect to total distance run remained similar throughout all stages, emphasising the need of consistent doses of practice of each activity in a training programme throughout a sporting career (Figure 2B-F).

With regard to the Kenyan long-distance runners in this study, these results also matched the explanations of Wilber \& Pitsiladis (2012) for their continued sporting success. According to these authors, this success is a multifactorial phenomenon explained by different causes, such as genetics, physiology, biomechanics, psychology, socio-cultural issues and economics. Thus, their findings agree with MacNamara et al.'s (2016) criticism of DP theory regarding its inability to fully explain the performance achievement process, but should not detract from the fact that better, more intensive training remains a key factor in their superior performances (Hamilton, 2000). In terms of the different activities that influence performance in longdistance runners, results from this study differed substantially from studies on Canadian middle-distance runners (Young $\&$ Salmela, 2010), because accumulative practice in activities that showed a very important effect on the differentiation of performance groups in their study, such as weight training and technique drills, were not relevant in the present study. Social and 
cultural aspects directly influence the training methods for this particular group of exceptional Kenyan runners, and explains why most Kenyan long-distance runners have never accessed gymnasium facilities; thus, the evolution of their athletic excellence is absolutely different from athletes of Western origin (Casado \& Ruiz, 2017). Furthermore, some Kenyan athletes do not have a coach, and for a very high number of these athletes their development is marked by participating in a training group instead (Casado et al., 2014; Finn, 2013; Tanser, 2008), which is likely to suit key training sessions like tempo runs and easy runs. However, one particular limitation has to be acknowledged. As training data from the study participants were collected from one block of time per season (10 weeks before their major competition), training periodisation and the subsequent fluctuations in amounts of practice of the different activities throughout the season were not taken into consideration.

\section{CONCLUSIONS}

DP-related training sessions and easy runs could partially predict the achieved performances among runners, who were semi-elite, elite, and amongst the best long-distance runners in the world, after seven years of systematic training. Easy runs, which were not considered a DP activity by participants, were the more practised activity by these runners, and differed between groups. Tempo runs constituted the activity that most specifically characterised the training of Kenyan long-distance runners, and the implementation of this training activity for longdistance runners should be considered vital for success by coaches. Short-interval training also seems to be a necessary practice activity that differentiated the participants by performance. However, long-interval training was used considerably by all participants, although its accumulation did not differ across performance groups at any stage. Accordingly, coaches who wish to increase the intensity of training for their athletes should focus on adding tempo runs and short intervals (whilst always considering the risk of overtraining or injury on athletes) that 
appear to be crucial to Kenyan runners in building on their physiological and biomechanical traits to become world-class athletes.

\section{ACKNOWLEDGEMENTS}

The authors would sincerely like to acknowledge the outstanding contributions of the coaches and the athletes who participated in this study. The authors also gratefully thank the useful suggestions and advice provided by Dr Bradley Young in conducting this study.

\section{DISCLOSURES}

There is no disclosure of funding to report for this study. The authors report no conflict of interest 


\section{REFERENCES}

Baker, J. Côté, J., \& Deakin, J. (2005) Expertise in ultra-endurance triathletes early sport involvement, training structure, and the theory of deliberate practice. Journal of Applied Sport Psychology, 17, 64-78.

Baker, J. \& Young, B. (2014). 20 years later: Deliberate practice and the development of expertise in sport. International Review of Sport and Exercise Psychology, 7, 135-157.

Billat, V., Lepretre, P. M., Heugas, A. M., Laurence, M. H., Salim, D., \& Koralsztein, J. P. (2003). Training and bioenergetics characteristics in elite male and female Kenyan runners. Medicine and Science in Sports and Exercise, 35, 297-304.

Blair, S. N., Dowda, M., Pate, R. R., Kronenfeld, J, Howe, H. G., Parker, G., Blair, A., \& Fridinger, F. (1991). Reliability of long term recall of participation in physical activity by middle age men and women. American Journal of Epidemiology, 133, 266-275.

Casado, A., Ruíz, L. M., \& Graupera, J. L. (2014). La percepción que los corredores kenianos tienen de sus actividades de entrenamiento. Cuadernos de Psicología del Deporte, 14, 99-110.

Casado, A., \& Ruiz-Pérez, L. M. (2017). Los corredores kenianos y españoles de larga distancia y su práctica deliberada. Revista de Psicología del Deporte, 26, 55-61.

Cohen, J. (1988). Statistical power analysis for the behavioural sciences ( $2^{\text {nd }}$ ed.). Hillsdale, NJ: Lawrence Erlbaum. 
Ericsson, K. A. (2013). Training history, deliberate practice and elite sports performance: An analysis in response to Tucker and Collins review "What makes champions?" British Journal of Sports Medicine, 47, 533-535.

Ericsson, K. A., Krampe, R. T., \& Tesch-Römer, C. (1993). The role of deliberate practice in the acquisition of expert performance. Psychological Review, 100, 363-406.

Falkner, K. L., Tervisan, M., \& McCann, S. E. (1999). Reliability of recall of physical activity in the distant past. American Journal of Epidemiology, 150, 195-205.

Finn, A. (2013). Running with the Kenyans. London, Faber.

Hambrick, D. Z., Oswald, F. L., Altmann, E. M., Meinz, E. J., Gobet, F., \& Campitelli, G. (2014). Deliberate practice: Is that all it takes to become an expert? Intelligence, 45, 34-45. doi:10.1016/j.intell.2013.04.001.

Hamilton, B. (2000). East African running dominance: What is behind it? British Journal of Sports Medicine, 34, 391-394.

Hanley, B. (2016). Pacing, packing and sex-based differences in Olympic and IAAF World Championship marathons. Journal of Sports Sciences, 34, 1675-1681.

Hanley, B. (2018). Pacing profiles of senior men and women at the 2017 IAAF World Cross Country Championships. Journal of Sports Sciences, 36, 1402-1406. 
Hayman, R., Polman, R., \& Taylor, J. (2012). The validity of retrospective recall in assessing practice regimes in golf. International Journal of Sport and Exercise Psychology, 10, 329-337.

Helsen, W. F., Starkes, J. L., \& Hodges, N. J. (1998). Team sports and the theory of deliberate practice. Journal of Sport and Exercise Psychology, 20, 13-35.

Hodge, T. \& Deakin, J. M. (1998). Deliberate practice and expertise in the martial arts: The role of context in motor recall. Journal of Sport and Exercise Psychology, 20, 260-279.

Hodges, N. J., Augaitis, L., \& Crocker, P. R. E. (2016). Sport commitment and deliberate practice among male and female triathletes. International Journal of Sport Psychology, 47, $652-665$.

Hodges, N. J., Kerr, T., Weir, P. L., \& Nananidou, A. (2004). Predicting performance times from deliberate practice hours for triathletes and swimmers: what, when and where is practice important? Journal of Experimental Psychology: Applied, 10, 219-237.

Hodges, N. J., \& Starkes, J. L. (1996). Wrestling with the nature of expertise: A sport specific test of Ericsson, Krampe \& Tesh-Römer's (1993) theory of “deliberate practice”. International Journal of Sport Psychology, 27, 400-424.

Hopkins, W.G., Marshall, S. W., Batterham, A. M., \& Hanin, J. (2009). Progressive statistics for studies in sports medicine and exercise science. Medicine and Science in Sports and Exercise, 41, 3-13. 
IAAF (2018). Records \& lists. Retrieved from https://www.iaaf.org/records/toplists/

Kenneally, M., Casado, A., \& Santos-Concejero, J. (2018). The effect of periodization and training intensity distribution on middle- and long-distance running performance: A systematic review. International Journal of Sports Physiology and Performance, 9, 1114-1121.

Legaz, A., \& Eston, R. (2005). Changes in performance, skinfold, thicknesses and fat patterning after three years of intense athletic conditioning in high level runners. British Journal of Sports Medicine, 39, 851-856.

MacNamara, B. N., Hambrick, D. Z., \& Oswald, F. L. (2014). Deliberate practice and performance in music, games, sports, education, and professions: A meta-analysis. Psychological Science, 25, 1608-1618. doi:10.1177/0956797614535810.

MacNamara, B. N., Moreau, D., \& Hambrick, D. Z. (2016). The relationship between deliberate practice and performance in sports: A meta-analysis. Perspectives on Psychological Science, 11, 333-350.

Midgley, A. W., McNaughton, L. R., \& Jones, A. M. (2007). Training to enhance the physiological determinants of long-distance running performance: Can valid recommendations be given to runners and coaches based on current scientific knowledge? Sports Medicine, 37, 857-880. 
Spiriev, A. (2017). Visible body: IAAF scored tables updated for 2017. IAAF publishing. Recovered from: https://www.iaaf.org/news/iaaf-news/scoring-tables-2017.

Stöggl, T. L., \& Sperlich, B. (2015). The training intensity distribution among well-trained and elite endurance athletes. Frontiers in Physiology, 6, 295. doi: 10.3389/fphys.2015.00295.

Tanser, T. (2008). More fire. How to run the Kenyan way. Yardley: Westholme.

Wilber, R. L., \& Pitsiladis, Y. P. (2012). Kenyan and Ethiopian distance runners. What makes them so good? International Journal of Sports Physiology and Performance, 7, 92-102.

Young, B. W., \& Salmela, J. H. (2002). Perceptions of training and deliberate practice of middle distance runners. International Journal of Sport Psychology, 33, 167-81.

Young, B. W., \& Salmela, J. H. (2010). Examination of practice activities related to the acquisition of elite performance in Canadian middle distance running. International Journal of Sport Psychology, 41, 73-90. 